\title{
RELAÇÕES DE GÊNERO NA MATEMÁTICA: \\ O PROCESSO HISTÓRICO-SOCIAL DE AFASTAMENTO \\ DAS MULHERES E ALGUMAS BRAVAS TRANSGRESSORAS
}

\author{
GENDER RELATIONS IN MATHEMATICS: THE HISTORICAL-SOCIAL \\ PROCESS OF WOMEN'S EXCLUSION AND SOME BRAVE TRANSGRESSORS
}

\begin{abstract}
Resumo
O presente trabalho aborda questões de gênero na área da Matemática, a partir da relação das mulheres com o saber matemático e sua participação na construção e propagação deste. Para isso analisou-se, através de uma regressão histórica apoiada nas obras de Muraro (1993), Tosi (1998) e outros, como se deu o processo de exclusão feminina desse meio, evidenciado através de diversos discursos e práticas recorrentes em nosso cotidiano. Logo após, reconhecendo a necessidade de evidenciar a participação e contribuição feminina ao campo da matemática, são apresentados breves relatos biográficos de mulheres matemáticas, aqui chamadas afetuosamente de bravas transgressoras. Tem por objetivo provocar discussão acerca da temática, levando o leitor a questionar-se sobre o porquê de ainda termos poucas mulheres nos ramos das ciências exatas.
\end{abstract}

Palavras-chave: Relações de gênero. Mulheres. Matemáticas.

\begin{abstract}
This work aims at discussing gender issues concerning the field of Mathematics from the relationship between women and mathematical knowledge, as well as women's role in its construction and propagation. For this purpose, it was analyzed, through a process of historical regression based on Muraro (1993) and Tosi's (1998) studies, among others, how female exclusion from the above mentioned field has been occurring which is highlighted by means of several recurrent discourses and practices in our daily lives. Subsequently, by considering the importance of women participation and contribution in the field of Mathematics, a brief biographical reports on female mathematicians, who are kindly called brave transgressors in this work, are going to be presented. Thus, it also aims at provoking discussion on this matter in order to lead the reader to question the reason why there are few women in the branches of the exact sciences.
\end{abstract}

Keywords: Gender relations. Women. Mathematicians. 


\section{Considerações Iniciais}

A Matemática, uma das mais antigas ciências que se tem relato e tida como a mãe de todas as outras, é, para muitos, um campo de atuação masculina. Geralmente chegamos a esta conclusão através de, entre outros, dois fatores consideráveis: a escassez de pensadoras e construtoras de saberes matemáticos que nos é apresentada, e a diferença expressiva do número de homens e mulheres cursando áreas voltadas para as ciências exatas e/ou atuando no mercado de trabalho dessa área, principalmente dentro das academias, no ensino de Matemática.

Para comprovar rapidamente essa realidade basta folhear um livro didático de matemática de qualquer série da Educação Básica, ou ainda, perguntar a um aluno prestes a concluir o Ensino Médio o nome de, pelo menos, uma matemática ou qualquer saber matemático atribuído a uma mulher que ele conheça. Outro exemplo que pode ser citado é o Instituto Nacional de Matemática Pura e Aplicada (IMPA), que em meio a seu quadro de 50 pesquisadores, possui apenas uma mulher ${ }^{1}$, ou ainda a Sociedade Brasileira de Matemática (SBM), que, dos seus 14 membros do Conselho Diretor, apenas três são mulheres ${ }^{2}$. Corroborando com essa linha de raciocínio, Fernandes (2006, p. 39-40) nos diz:

Tomando como referência o conceito de campo de Bourdieu (2002), o campo da matemática é um lugar onde os atores (matemáticos) travam uma luta em torno de interesses específicos, que caracterizam a área. A dominação deste campo é garantida pela acumulação de capital (conhecimentos matemáticos avançados) que representa um certificado de competência historicamente conquistado e conservado pelos homens. Esta realidade é destacada na formação básica, pois nos livros didáticos os principais teoremas e procedimentos da matemática homenageiam matemáticos famosos, nomeando-os com o seu nome, a exemplo do Teorema de Tales de Milleto, o Teorema de Pitágoras, do Teorema de Fermat, do Algoritmo de Euclides, do Crivo de Erastóstenes.

1 Dados disponíveis em http://www.impa.br/opencms/pt/pesquisa/ pesquisa_pesquisadores/pesquisadores_do_impa.html, acessado em 06 de março de 2017, às $23 \mathrm{~h} 30$

2 Dados disponíveis em http://www.sbm.org.br/institucional/organizacao/ conselho-diretor, acessado em 06 de março de 2017, às $23 \mathrm{~h} 36$
É muito fácil comprovar que as mulheres ainda estão à margem do processo de criação, descoberta e propagação dos saberes matemáticos, embora as pautas dos movimentos feministas, que lutam por equidade entre os gêneros e que surgem com mais força na chamada Primavera Feminista, estarem sendo cada vez mais abordadas e discutidas. Os discursos que envolvem mulheres e Matemática, em sua maioria, perpetuam a suposta inferioridade feminina, a incompatibilidade com o universo do saber, o não-pertencer da mulher ao campo matemático ${ }^{3}$. Contudo, dizer, a partir desse apanhado, que a Matemática é uma ciência masculina, é uma afirmação muito delicada, e que deixa uma enorme lacuna histórica, social e cultural.

E é do cerne dos questionamentos decorridos das percepções aqui expostas que surge este estudo, a fim de buscar entender o porquê da ausência e se, de fato, há realmente ausência das mulheres nesse meio. Para isso, esta pesquisa dispõe-se a fazer uma análise histórica, sob a ótica feminista, da relação das mulheres com o saber e, posteriormente, com as ciências, dando ênfase à Matemática, buscando identificar elementos essenciais para o processo de afastamento feminino da Matemática, através do diálogo com autores desse campo, e, logo após, propõe-se um aprofundamento nas histórias de vida e contribuições intelectuais de algumas estudiosas da área, a fim de prestigiar seus achados, homenageando-as, dessa forma.

\section{A relação da mulher com o saber: uma análise histórico-social}

Diferentemente do que se pensava em outras épocas, hoje temos a comprovação científica - por mais incrível que pareça a necessidade de se comprovar isso cientificamente - de que as mulheres são biologicamente tão capazes quanto os homens de aprender e desenvolver conhecimento nas áreas das ciências exatas. Cai por terra, assim, o mito de que ciência, de modo geral, é coisa de homem. Dessa forma, podemos concluir que esse discurso é uma mera convenção social, que se perpetua, ainda que imperceptivelmente, e povoa o inconsciente das jovens e dos jovens, antes mesmo de chegarem às escolas.

3 Para saber mais sobre discurso, mulheres e matemática cf. Souza \& Fonseca (2010) 
Para se ter uma melhor compreensão dessa situação de distanciamento e exclusão das mulheres com as ciências é necessário, portanto, que se faça uma regressão, a fim de entender a trajetória da história da humanidade, as construções sociais que se deram e a relação da mulher com o saber ao longo das eras. É o que faremos nesta sessão.

A princípio, as tribos nômades sobreviviam através de tudo que a natureza lhes fornecia, sem desenvolver ainda armas que lhes possibilitassem caçar grandes presas. Vivia-se nessa época um regime matricêntrico. Não havia a necessidade de força física para a sobrevivência, logo não havia diferenciação expressiva entre homens e mulheres. Além disso, a mulher era tida como sagrada, por ser capaz de reproduzir a espécie. Nesse período não se tinha ainda o conhecimento da participação do homem no processo de procriação, assim o dom da vida era da mulher.

A esse ponto, como defende a autora Rose Marie Muraro, em seu livro A História do Feminino e Masculino (2007), havia um sentimento de paz generalizada, onde, ao invés da competitividade e agressividade vista nas épocas seguintes, reinava a cooperação e a integração entre homem e natureza. Até que vem a descoberta da função masculina na reprodução humana, e, podendo controlá-la, passa a controlar também a sexualidade feminina. Eis que surge o patriarcado. Nas palavras de Muraro (1993, p. 6), “Ao contrário da mulher, que possuía o 'poder biológico', o homem foi desenvolvendo o 'poder cultural' à medida que a tecnologia foi avançando".

Uma vez que nas sociedades matricêntricas desconhecia-se a participação dos homens na reprodução, não havia o problema da hereditariedade de bens ou, principalmente, de poder. Após tomar conhecimento disso, a reprodução passa automaticamente a estar diretamente relacionada com herança e transmissão de bens, fazendo com que a sexualidade feminina fosse restringida. Eis que surgem os contratos matrimoniais como conhecemos hoje.

Nesse mesmo período, surge o processo de agricultura, o poder de arar a terra e de não precisar mais deslocar-se de um local para o outro para sobreviver. Vale ressaltar o fato de que foram as mulheres as primeiras coletoras e as primeiras a descobrirem os ciclos da natureza, ao compararem com o ciclo do próprio corpo. Estabelecem-se, assim, as primeiras aldeias, dando início ao processo de civilização. Para Muraro (1993) é aí que surge as sociedades patriarcais, onde os valores são masculinos e são os homens os responsáveis por sua transmissão. "Já não são mais os princípios feminino e masculino que governam juntos o mundo, mas, sim, a lei do mais forte" (p. 7).

Nesse contexto, quanto mais filhos, mais
soldados e mais mão-de-obra barata para arar
a terra. As mulheres tinham a sua sexualidade
rigidamente controlada pelos homens. O
casamento era monogâmico e a mulher era
obrigada a sair virgem das mãos do pai para
as mãos do marido. Qualquer ruptura desta
norma podia significara morte. Assim também
o adultério: um filho de outro homem viria
ameaçar a transmissão da herança que se fazia
através da descendência da mulher. A mulher
fica, então, reduzida ao âmbito doméstico.
Perde qualquer capacidade de decisão no
domínio público, que fica inteiramente
reservado ao homem. A dicotomia entre o
privado e o público torna-se, então, a origem
da dependência econômica da mulher, e esta
dependência, por sua vez, gera, no decorrer
das gerações, uma submissão psicológica que
dura até hoje. (MURARO, 1993, p. 7-8).

Essa análise é pertinente e necessária para que entendamos a inversão do local da mulher na sociedade, passando do centro para as zonas periféricas. De um ser antes cultuado por perpetuar a espécie, passa a ser subordinada e inteiramente submissa ao homem. Muraro (1993), em sua breve Introdução Histórica ao livro Malleus Maleficarum ${ }^{4}$, de Heinrich Kramer e James Sprenger, aborda de forma muito detalhada como se deu essa transição do mundo matricêntrico para a sociedade patriarcal.

A autora se utiliza de uma análise das religiões, enquanto indicadores de cultura e hábitos sociais. Fala da transição das primeiras religiões que se tem registro, nas quais se cultuavam deusas, cujos traços eram geralmente fartos, curvilíneos, responsáveis por gerar toda a vida (como Géia, por exemplo, na mitologia grega, ou ainda Nanã Buruquê, mãe de todos os orixás da Umbanda) para as religiões contemporâneas, onde o ser criador e todopoderoso é expressamente masculino, como, por exemplo, as hegemônicas religiões cristãs da atualidade.

4 Publicado originalmente no ano de 1487, esse livro é considerado a Bíblia dos Inquisidores, por estar presente em praticamente todo julgamento da inquisição da Igreja Católica contra pessoas acusadas de bruxaria, na sanguinária Caça às Bruxas, entre os séculos XVI e XVII. 
Ao contrário das culturas primitivas, Javé é deus único, centralizador, dita rígidas regras de comportamento cuja transgressão é sempre punida. Nas primitivas mitologias, ao contrário, a Grande Mãe é permissiva, amorosa e não coercitiva. $\mathrm{E}$ como todos os mitos fundantes das grandes culturas tendem a sacralizar os seus principais valores, Javé representa bem a transformação do matricentrismo em patriarcado. (MURARO, 1993, p. 9).

Além disso, a própria forma de criação da humanidade, segundo a religião com maior número de adeptos atualmente, é muito representativa. No mito cristão, Deus cria um homem e tira dele (de uma costela sua, mais especificamente) a mulher. Há aqui, claramente, uma inversão do parto, onde, ao invés da mulher, o homem é o ser que primeiramente gerou a vida da espécie. Sem falar que a culpa da desgraça dos primeiros habitantes do Éden, o "pecado original”, recai inteiramente sobre Eva, que comeu o fruto (mas não sozinha) da única árvore proibida no jardim, curiosamente conhecida como árvore da vida, ou árvore do conhecimento.

É interessante notar que os frutos da tal árvore da vida trariam o conhecimento do bem e do mal, em outras palavras, trariam o saber. E que o saber, assim com a mulher, que se deixou seduzir por ele, são indesejáveis e passíveis de punição. A partir de então, o homem, expulso do paraíso e fadado à desgraça de precisar da terra para sobreviver, começa a dominá-la. Essa dominação representa uma ruptura simbólica com o sistema matricêntrico, que cultivava uma relação de dependência e harmonia com a natureza, enquanto o novo sistema que se projeta propõe um afastamento. Muraro (1993) faz ainda duas observações muito importantes na interpretação desse trecho bíblico:

A primeira é que o pivô das duas tragédias, a individual e a coletiva, é a mulher; e a segunda, que o conhecimento condenado não é o conhecimento dissociado e abstrato que daí por diante será o conhecimento dominante, mas sim o conhecimento do bem e do mal, que vem da experiência concreta do prazer e da sexualidade, o conhecimento totalizante que integra inteligência e emoção, corpo e alma, enfim, aquele conhecimento que é, especificamente na cultura patriarcal, o conhecimento feminino por excelência. (p.10-11).
Mas enquanto o livro sagrado dos cristãos era escrito, o patriarcado ia ganhando espaço nas civilizações que, outrora, eram matricêntricas. $\mathrm{Na}$ Grécia, por exemplo, a homossexualidade era prática comum entre os homens, que se deitavam com as mulheres apenas para reproduzir, considerando essa uma relação impura; e em Roma, berço do termo pater familias, embora se tivesse uma sexualidade mais liberal, tanto para homens quanto para mulheres, as principais decisões do governo eram tomadas por homens, exclusivamente.

Após essa era das civilizações do chamado Antigo Mundo, houve a consolidação do cristianismo como religião oficial do Império Romano, e, por consequência, de grande parte do ocidente. Dá-se início a Idade Média, época onde os princípios e valores eram ensinados pela Igreja de geração em geração, a fim de, do ponto de vista do gênero, formar a mulher perfeita, que soubesse e ocupasse exatamente o seu lugar na sociedade: o de submissão e dependência em relação ao sexo masculino.

Destacamos aqui que, por muitas vezes, ainda nesse período, ouvimos falar de mulheres líderes que tiveram extrema importância e destaque nas histórias desses lugares. E esse aspecto, pode muito bem ser entendido nas palavras de Muraro (1993), quando diz que "as mulheres eram jogadas para o domínio público quando havia escassez de homens e voltavam para o domínio privado quando os homens reassumiam o seu lugar na cultura" (p.13). Em outras palavras, a mulher tomava a liderança e o "poder" apenas na ausência do homem, estando ela na verdade usando o poder dele, não um seu próprio.

E essa dominação, cuja maior força vinha da religião e da construção social que se dava a partir desta, foi expandindo até que encontra seu ápice no século XVII, num episódio que ficou marcado na história da humanidade como uma imensa mancha misógina: a caça às bruxas. Os números são espantosos. Há autores que relatam algo próximo à casa das cem mil mulheres queimadas vivas, acusadas de bruxaria e heresia, durante os quatro séculos de inquisição.

Eram as mulheres que, desde as mais remotas eras, manipulavam ervas e conheciam os ciclos da natureza, atuavam como curandeiras, parteiras, xamãs, nas tribos mais antigas, enfim, detinham o saber que lhe era transmitido de gerações em gerações. Eram elas que cuidavam da saúde das populações campestres, uma vez que estas não tinham 
acesso à recém-nascida medicina moderna. E esse saber ia de encontro ao que vinha sendo pregado pela já consolidada doutrina cristã, no que tangia ao lugar das mulheres e à sua formação, como explica Tosi (1998):

A mudança drástica ocorrida a partir do fim do século XV comportava a demonização da mulher, principalmente da mulher sábia. Aqueles conhecimentos empíricos, que as mulheres dominavam e praticavam desde épocas ancestrais, foram considerados suspeitos. Afirmava-se que dada sua fraqueza física e moral, sua limitada inteligência, sua carência de raciocínio, sua sexualidade incontrolável e sua lubricidade, a mulher era a vítima privilegiada de Satã. Seu saber e seus misteriosos poderes só podiam ter sido adquiridos por meios ilícitos, pactuando com o demônio. Foi essa a imagem da bruxa elaborada com amplos detalhes durante mais de um século por inquisidores católicos, padres protestantes e a elite burocrática criada pelos estados emergentes. (p. 375).

A partir daí, começou-se a construir uma imagem da mulher como ser inferior, fragilizado, suscetível ao pecado e ao demônio, que estaria predisposta a trazer, assim como Eva trouxe, a desgraça para a humanidade. "O pensamento misógino medieval fazia tudo para ressaltar a malignidade natural da fêmea e sua predestinação para o Mal" (NOGUEIRA, 1995, p. 80 apud CUSTÓDIO, 2012, p. 27). Essa construção se deu através de infindáveis obras, quase didáticas, que reforçavam esse arquétipo feminino, bem como ensinavam a reconhecer e erradicar a presença maligna instrumentalizada em nosso meio através da mulher. Talvez a mais conhecida destas obras tenha sido o, já citado, Malleus Malleficarum. E, assim, "através desse conjunto de obras, redigidas pela Igreja, pretendiase provar a presença do Diabo na terra, bem como a sua maldade por meio das bruxas, relacionando diretamente o mal à mulher" (GEVERH; DE SOUZA, 2014, p. 117).

Por outro lado, para além da concepção e consequência cultural e social, há quem argumente que a caça às bruxas guardou consigo um teor político e econômico, tendo sido, além de uma jogada violenta de repressão à sexualidade feminina e, consequentemente, ao sexo feminino, uma forma de preparar o terreno para o capitalismo, que já estava em gestação no seio do sistema feudal, como explica Muraro (1993):
Este "expurgo" visava recolocar dentro de regras de comportamento dominante as massas camponesas submetidas muitas vezes aos mais ferozes excessos dos seus senhores, expostas à fome, à peste e à guerra e que se rebelavam. E principalmente as mulheres. [...] Começa a se construir ali o corpo dócil do futuro trabalhador que vai ser alienado do seu trabalho e não se rebelará. [...] Todos, homens e mulheres, passam a ser, então, os próprios controladores de si mesmos a partir do mais íntimo de suas mentes. (p. 14-15).

É assim alcançado, através desse atentado feroz ao feminino, o real objetivo da caça às bruxas: reprimir e colocar sobre rédeas curtas a relação da mulher com o saber, permitindo a ela apenas o âmbito doméstico e o saber necessário para cuidar da casa, criar os filhos e servir o marido. E essa formação seguiu-se pelos séculos seguintes, passando pelo Iluminismo, onde as mulheres já demandavam participar da fomentação intelectual que ocorria, até chegarmos no período da Revolução Francesa. Esse recorte é necessário, pois as sociedades que surgiam a partir daí tinham como forte característica o pluralismo e a aceleração da mudança social.

Sendo assim, nas concepções democráticas que começam a nascer, não existem mais autoridades que teriam o privilégio do saber e de determinar o que era certo ou o errado, como acontecia antes da Revolução Francesa. Agora cada indivíduo tem o poder singular de falar, de conhecer e de seguir o seu próprio julgamento. Por isso, para compreender os acontecimentos dos séculos XIX, XX e XXI e em particular a relação mulheres/saberes/instrução é imprescindível discutir este momento chave na história do mundo ocidental: A Revolução Francesa. Assistiu-se neste momento ao nascimento das democracias ocidentais cuja essência é a igualdade (igualdade jurídica e não social e econômica). (MOREIRA et. al, 2010, p. 2-3).

As mulheres, cada vez mais fortemente, reivindicavam seu direito de aprender. E, em resposta a essa demanda, pensadores do Século das Luzes, como Rousseau, em seu livro Emile ou de l'Éducation (1762), posicionaram-se quanto ao direito do saber à mulher. Afirma o autor: 
(...) toda a educação das mulheres deve ser feita com relação aos homens. Agradá-los, ser-lhes úteis, fazer-se amar e estimar por eles, educá-los quando jovens, cuidá-los quando adultos, aconselhá-los, consolá-los, fazer-lhes a vida agradável e doce: esses são os deveres das mulheres de todas as épocas e o que deve lhes ser ensinado desde a infância. (ROUSSEAU, 1966, p. 475 apud TOSI, 1998, p. 379).

Além destes, médicos influentes e de grande prestígio na época insistiam em afirmar que a fisiologia feminina "condiciona o organismo das mulheres para desempenhar seu papel precípuo de mãe e esposa. Toda atividade intelectual é desaconselhada por contrariar seu destino biológico" (TOSI, 1998, p. 379). A ideia de uma mulher instruída era perigosa aos olhos dos homens, por ameaçar a "ordem natural" (que de natural nada teve, como vimos até aqui) da sociedade.

Por outro lado, uma linha de raciocínio diferente convergia para a educação da sociedade baseada em planos de ensino: um para o homem e outro para a mulher. $\mathrm{O}$ ensino voltado à mulher, diferentemente do voltado ao homem, limitava a exposição da mesma a vastos e profundos conhecimentos, garantindo apenas aqueles suficientes para sua atuação em seu lugar social. John Locke, renomado filósofo inglês desse período, preconizava uma educação para as mulheres, a fim de torná-las boas mães. "Pode-se dizer que a ideologia mais representada no século XVIII consiste em considerar que o homem é a causa final da mulher" (MOREIRA et al., 2010, p. 5). A grande questão era "como educar, conforme as exigências do mundo moderno, sem deixar o lado subversivo dessa modernidade corromper a alma feminina" (p. 6).

Entretanto, esse leve burburinho, que começou a tomar forma nos séculos XVII e XVIII, foi o precursor do discurso de igualdade de ensino e instrução entre homens e mulheres. Tal discurso, associado a transgressão de bravas mulheres que, estando à frente de sua época, dedicaram suas vidas ao estudo e à luta contra a injustiça de gênero, como veremos a seguir, permitiu que hoje, pudessem gozar o acesso a condições igualitárias de educação aos sexos, muito embora, ainda possamos sentir as marcas desse processo de afastamento das mulheres ao saber, manifestadas através do machismo velado que ainda existe nessa área.

\section{Algumas bravas transgressoras}

A partir do apanhado a respeito da relação com o saber, feito anteriormente, é possível notar que, historicamente, demandou muito esforço, dedicação, renúncia e teimosia por parte das mulheres que estavam dispostas a assumir e mergulhar de cabeça nessa paixão pelo saber, principalmente, pelas ciências, tais como a Matemática.

Em meio às milhares que foram proibidas, torturadas, e até mortas, por envolverem-se com o conhecimento, agindo, assim, de maneira contrária ao que se esperava do sexo feminino, a história registra nomes de mulheres que bravamente se opuseram ao sistema opressor e conseguiram galgar caminhos difíceis de percorrer, ou ainda, nunca antes percorridos. Podemos achar que foram poucas ou, até mesmo, pouquíssimas mulheres que enveredaram pelos ramos da matemática, mas como nos diz Moreira et al. (2010):

\begin{abstract}
Proporcionalmente aos obstáculos encontrados, o número de mulheres cientistas em todas as épocas é relativamente grande e seria totalmente errôneo achar que o progresso científico e tecnológico aconteceu sem elas (p. 11).
\end{abstract}

Notavelmente, "quando se fala em mulher e ciência, a reação imediata é de indicar a ausência de mulheres no desenvolvimento desta atividade ao longo da história". (PÉREZ-SEDEÑO \& GARCIA, 1992, apud CAVALARI, 2010, p. 3). Entende-se, dessa forma, que há a necessidade de, além de indicar os possíveis fatores que contribuíram para essa exclusão, divulgar a obra e a vida dessas bravas mulheres. Faremos, assim, um breve relato biográfico de algumas das mais conhecidas matemáticas, ressaltando que houve tantas outras, conhecidas e desconhecidas, que tiveram igual importância e que também deixaram grandes contribuições para a área.

A primeira de quem falaremos é Hipátia (Hipácia é também uma grafia adotada), nascida em Alexandria, no ano de 370. "Hipátia é reconhecida como a primeira mulher a ter significante impacto no campo da matemática, e alguns a tem referenciado como a "mãe da matemática" (KOCH, 1996 apud HUFF, 2011, p. 04, tradução do autor). Era filha do 
matemático, filósofo e astrônomo Teon (335-405), conhecido por ter feito uma revisão dos Elementos, de Euclides. Quando adolescente, viajou para Atenas para aperfeiçoar seus conhecimentos e, ao voltar ao Egito, tornou-se professora de filosofia e matemática.

É conhecida pelo seu trabalho nas secções cônicas, introduzidas primeiramente por Apolônio. Desenvolveu as ideias das hipérboles, parábolas e elipses enquanto editava seu texto Nas Cônicas de Apolonio. Ficou também conhecida por escrever comentários em livros, dando explicações de difíceis e densos tópicos, sendo de mais fácil entendimento do que nos livros originais (KOCH, 1995 apud HUFF, 2011, p. 05, tradução do autor).

A maior parte da obra escrita por Hipátia foi perdida, mas no séc. XV foi encontrada na Biblioteca do Vaticano uma cópia do seu comentário sobre a obra do matemático grego Diofanto. Hipátia era fervorosa adepta do paganismo e, graças a isso, conquistou inimizade entre as massas cristãs que surgiam na época. Em março de 415 , ao voltar para sua casa, foi atacada por uma multidão de fiéis que lhe arrancaram as roupas e, barbaramente, assassinaram-na. Alguns estudiosos especulam que, além de motivações religiosas, houveram questões políticas envolvidas em sua morte.

"Após seu assassinato, vários estudiosos fugiram de Alexandria e o foco na educação e aprendizado começou a diminuir. Como resultado, a matemática não foi formalmente estudada em Alexandria nos 1000 anos que se seguiram" (KOCH, 1997 apud HUFF, 2011, p. 5-6, tradução do autor). A morte de Hipátia representa, dessa forma, o início do declínio do desenvolvimento e formalização matemática que vinham acontecendo até então.

É interessante observar, como aspecto pertinente a essa pesquisa, a abordagem que livros amplamente utilizados no ensino de História da Matemática fazem - ou deixam de fazer - dessas mulheres. Boyer, em seu célebre História da Matemática ${ }^{5}$ (1996), lembra de Hipátia, em decorrência a menção de seu pai, colocando dessa forma:

5 Coincidentemente traduzido por Elza Furtado Gomide, primeira mulher brasileira a receber o título de Doutora em Ciências, tendo Matemática como área de concentração, de quem falaremos mais a frente.
Teon também é responsável por uma importante edição de Os elementos que se preservou; é lembrado também como o pai de Hipátia, uma jovem culta que escreveu os comentários sobre Diofante, Ptolomeu e Apolônio. (BOYER, 1996, p. 129)

Além de defini-la apenas como uma "jovem culta", Boyer (1996) rebate o ponto de vista de que sua morte tenha sido, de fato, o fim da matemática antiga, atribuindo este fim à morte de Boécio (cerca de 480-524), filósofo e matemático romano, que "embora possa ter sido o principal matemático produzido pela Roma antiga, o nível de sua obra está muito abaixo do nível característico dos autores gregos" (BOYER, 1996, p. 130). Contudo, mesmo com esses fortes comentários e abordagem mínima, Boyer consegue ir além de Roque e Pitombeira, que sequer citam Hipátia, em seu Tópicos de História da Matemática (2012).

De todo modo, há aqui uma enorme lacuna no registro de outras mulheres envolvidas com a matemática. Como visto anteriormente, vários fatores convergiram para esse afastamento das mulheres ao saber, dentre eles, fortemente, o cristianismo, como mostra o episódio trágico que levou o fim da maior matemática do Egito antigo. Os mecanismos sociais, culturais e políticos, abordados na seção anterior, mantiveram, com êxito, a presença feminina longe da matemática até meados do século XVIII, data que surge nossa próxima protagonista.

Gabriele Émilie Le Tonnelier De Breteuil, comumente conhecida como Madame - ou Marquesa Du Châtelet, nasceu em 1706, em Versailles, na França. Filha de uma família influente, Gabriele recebeu, desde pequena, uma excelente educação. Aos doze anos já era fluente em latim, italiano, grego e alemão, vindo a publicar posteriormente traduções em francês de obras clássicas da Grécia antiga. Também "apreciava muito a dança, alcançou um nível bom como cravista, [e] cantava em peças de ópera e era uma atriz amadora" (OLIVEIRA, 2011, p. 26).

Um fato intrigante na vida dessa matemática foi seu matrimônio com o Marquês Du Châtelet-Lomont daí sua alcunha de Marquesa. Casaram-se não por amor, mas para satisfazer acordos prévios. Nasceram três filhos desse casamento e " (...) vendo cumprido o seu papel como esposa, Émilie e seu marido concordaram continuar 
casados e viver em conjunto na mesma residência, porém, terem vidas independentes" (OLIVEIRA, 2011, p. 26). Eram comuns romances extraconjugais, tendo sido um deles com um renomado nome no meio científico: Voltaire. A relação dos dois foi de grande intensidade romântica e intelectual, tendo vivido juntos durantes anos, reclusos em Cirey.

Quanto aos seus trabalhos, Emilie "foi a primeira mulher física reconhecida pela comunidade cientifica que deixou vários tratados" (BADINTER, 1986 apud MOREIRA et. al, 2010, p. 08). Junto com Voltaire desenvolveu os Eléments de la Philosophia de Newton. Estudou Leibniz e Gravesande, e deu sua contribuição nos tratados sobre energia de um objeto em movimento, chegando a conclusões diferentes das de pensadores como Isaac Newton, Voltaire e outros.

Em 1737, Émilie Du Châtelet publicou o ensaio "Dissertation sur la nature et la propagation $d u$ feu", baseado em suas pesquisas com a ciência do fogo, predizendo o que hoje se conhece pelo nome de radiação infravermelha e a natureza da Luz. Seu livro "Institutions de Physique" saiu do prelo em 1740 e foi apresentado como uma avaliação das novidades no campo da ciência e da filosofia". (OLIVEIRA, 2011, p. 27).

Porém seu último romance mostrou ser fatal. Tendo mal entrado em seus quarenta anos, Émilie se envolveu num romance com um poeta, resultando em uma gravidez. Temendo não sobreviver a gravidez, devido sua idade, concluiu rapidamente a obra que seria um de seus maiores feitos no campo da ciência: a tradução ao francês, com importantes comentários, da célebre "Principia Mathematica" (1687), de Newton. Como se previsse, Du Châtelet morreu dias após o parto, aos quarenta e três anos, devido a um embolismo.

Nascida em Milão, no ano de 1718, Maria Gaetana Agnesi foi a primeira mulher a ter notoriedade e reconhecimento oficial no meio científico de sua época e, ainda, a primeira a ser chamada de matemática no Ocidente, além de linguista e filósofa. Teve uma excelente educação, orientada por seu pai que era professor de Matemática na Universidade de Bolonha, e já aos nove anos tem um discurso seu publicado em latim, onde defendia a educação superior para mulheres.
Aos vinte anos, Agnesi publicou uma coletânea de 190 ensaios intitulados 'Propositones Philosophicae', onde relatava sobre elasticidade, mecânica, hidromecânica, mecânica celeste, gravitação, química, botânica, zoologia e mineralogia, além de defender mais uma vez a educação superior para mulheres. Esses escritos foram baseados nos encontros dos intelectuais em sua casa. [...] Aos trinta anos, Agnesi publicou outro trabalho, com objetivo de ensinar seus irmãos, que foi de grande importância para a matemática. Esse foi um dos primeiros trabalhos de cálculo escrito de forma didática. A obra consiste em quatro volumes, abordando tópicos de Álgebra, Geometria Analítica, Cálculo, Trigonometria e Equações Diferenciais, com o título de 'Instituzioni Analitiche'. (OLIVEIRA, 2011, p. 29;30).

Agnesi desejava afastar-se da vida pública, feito que veio a realizar apenas após a morte de seu pai. Embora nunca tenha sido aceita na Academia francesa, foi indicada como professora de filosofia natural da Universidade de Bolonha pelo papa Benedito XIV, cargo que nunca chegou a assumir. Dedicou-se à vida religiosa e a obras de caridade até sua morte em 1799. Foi uma das poucas mulheres que ficaram registradas oficialmente na Matemática, a partir de seus achados. Hoje, encontramos seu nome em uma curva do terceiro grau, a "curva de Agnesi".

Nossa próxima protagonista é Marie-Sophie Germain (1776-1831), uma parisiense de classe média que, devido à Revolução Francesa, passou sua infância e juventude confinada, tendo como única diversão estudar, escondida, os livros que compunham a farta biblioteca de sua casa. Sophie foi, por várias vezes, repreendida e castigada por seus pais, que não consideravam correto uma moça dedicar-se à matemática ou a qualquer outra ciência.

Uma vez superada, com dificuldade, a proibição de seus pais, Sophie desejava mais. Para estudar na recéminaugurada École Polythecnique (Escola Politécnica), que só aceitava homens em suas fileiras, assumiu a identidade de um aluno que havia deixado a escola e ido embora, por nome de Monsieur Antoine-Auguste Le Blanc. Dessa forma, passou a receber as lições em seu lugar e respondê-las semanalmente. Essa autêntica transgressora teve contato com grandes nomes da Matemática, tais como Joseph-Louis Lagrange, que foi seu professor e 
ficou impressionado ao descobrir que M. Le Blanc era, na verdade, uma mulher, e Carl Friedrich Gauss, com o qual se correspondeu por muito tempo, criando uma relação de amizade.

Em teoria dos números deixou muitos homens para traz, fazendo uma descoberta importante sobre o último teorema de Fermat. Antes de Sophie, muitos matemáticos já haviam tentado algum progresso, porém todos sem sucesso. [...] Além da matemática, Sophie estudou Química, Física, Geografia, História, Psicologia, (...) publicou dois volumes com seus trabalhos filosóficos, um dos quais mereceu o elogio de Auguste Comte. (...) Sua maior contribuição na física "Memória sobre as vibrações de placas elásticas", foi sem dúvida um trabalho que estabeleceu funções para a moderna teoria da elasticidade. (OLIVEIRA, 2011, p. 32)

Sophie ganhou ainda um concurso promovido pela Academia de Ciências da França, resolvendo um problema, proposto na época, sobre vibrações de membranas. De suas pesquisas nessa área surgiu o conceito de curvatura média de superfícies, que hoje é objeto de pesquisa de vários matemáticos na área de Geometria Diferencial. Seu trabalho recebeu elogios de Cauchy e Navier, que viriam a criar, posteriormente, juntos a Fourier, a teoria geral da elasticidade, para qual suas ideias foram fundamentais.

Sophie, sem dúvidas, deixou grandes contribuições à Matemática, além de inspiração, vinda de seu espírito inquieto, corajoso e que se recusava a aceitar o papel a ela designado por ser mulher. Entretanto, infelizmente, "no seu certificado de óbito, na rubrica profissão em vez de estar escrito 'matemática', está escrito 'rentière' ${ }^{\text {"' }}$ (MOREIRA et. al, 2010, p. 08).

Filha de nobres, Sofia Kovalevskaia nasceu em Moscou, no ano de 1850, e herdou do pai o interesse pela Matemática. Uma vez que na Rússia não se permitia mulheres nas universidades, nem tampouco que viajassem sendo solteiras, tratou logo de arranjar um casamento de conveniência, com Vladimir Kovalevsky. Sofia, então, passou a ter acesso aos estudos de Matemática e tornouse aluna do renomado matemático Karl Weierstrass, com quem trabalhou durante quatro anos, escrevendo grandes trabalhos que lhe renderiam, posteriormente, o título de doutora. Até a sua morte, decorrente de uma pneumonia, aos quarenta e um anos de idade, no auge de sua vida científica, Kovalevskaia atuou como professora de Matemática superior na Universidade de Estocolmo.

Amalie Emmy Noether (1882-1935), foi uma alemã, filha do conhecido algebrista Max Noether. É considerada, por muitos, como a maior matemática até hoje, tendo sido referida por Einstein como “o mais significante gênio matemático criativo já produzido desde que as mulheres começaram a cursar os estudos superiores"' (NEGREIROS; SOUZA; DE PAULA, 2016, p. 05). Emmy tentou ingresso na Universidade de Erlanger, onde seu pai lecionava e seu irmão estudava, porém, por ser do sexo feminino, apenas conseguiu ter aulas como ouvinte. Mesmo no século XX, a discriminação contra as mulheres permanecia, fazendo com que ela não conseguisse trilhar uma carreira em seu país. Foi, então, convidada para dar aulas em Oxford, no Somerville College e Bryn Mawr College, onde conheceu e passou a trabalhar com Einstein.

Um exemplo do não reconhecimento da mulher pela comunidade científica é o caso de Emmy Noether. Sabe-se que Einstein trabalhou durante dez anos na elaboração da teoria da relatividade ajudado, entre outros cientistas, por Emmy Noether (1882-1935). Ela realizou durante 15 anos um trabalho considerável e chegou à formulação de novos conceitos. No entanto, ela teve que esperar até 1921 para atingir o primeiro grau dos níveis na universidade e sem salário. (...)Também Maric Mileva (1875-1948) primeira esposa de Albert Einstein, matemática e física brilhante, participou ativamente da elaboração da teoria da relatividade, mas só Einstein recebeu o prêmio Nobel. (MOREIRA et al., 2010, p. 8).

No Brasil também temos grandes nomes femininos que dedicaram parte de suas vidas à Matemática. Uma delas é a pernambucana Maria Laura Mouzinho (19192013), que iniciou seu curso de Matemática na recémcriada Faculdade Nacional de Filosofia (FNFi) no ano de 1939. Dez anos depois Maria Laura consegue o título de doutora em Ciências (Matemática), com a defesa da tese "Espaços Projetivos Reticulados em Seus Sub-espaços". Já no início dos anos 50 esteve em Chicago, fazendo estudos de pós-doutorado.

6 Termo utilizado para designar quem vive de suas rendas próprias. 
Participou da criação do Centro Brasileiro de Pesquisa Física (CBPF) em 1949; em 1951 da criação do Conselho Nacional de Desenvolvimento Científico e Tecnológico (CNPq); em 1952 do Instituto de Matemática Pura e Aplicada (IMPA) (NEGREIROS; SOUZA; DE PAULO, 2016, p. 5).

Durante a ditadura militar foi com seu marido, José Leite Lopes, para a França, onde aprofundou-se nas questões de Educação Matemática, retornando ao Brasil em 1974.

Em 1976 foi criado o Grupo de Ensino e Pesquisa em Educação Matemática (GEPEM), que presidiu os oito anos iniciais, onde ela coordenava a primeira pesquisa em Educação Matemática no Brasil: "Projeto Binômio Professor - aluno na iniciação à educação matemática (uma pesquisa experimental)," resultante de convênio do GEPEM com MEC/INEP (contrato 06/79). (...) Participou ainda ativamente das reuniões que culminaram com a criação, em 27 de janeiro de 1988, da Sociedade Brasileira de Educação Matemática (SBEM) da qual é Presidente de Honra (OLIVEIRA, 2012, p. 41).

Outro nome de bastante relevância no cenário matemático nacional, é a, já citada, Elza Furtado Gomide (1925-2013). Filha e neta de professores de matemática, desenvolveu desde cedo sua paixão pela ciência, obtendo o título de Doutora em Matemática no ano de 1950. Foi sócia fundadora da SBM e foi também

(...) chefe do Departamento de Matemática da Faculdade de Filosofia, onde estruturou os cursos de Bacharelado e Licenciatura em Matemática. Fez Pós-Doutorado no Instituto Henry Poincaré, na cidade de Paris, na França, no período de 1962 à 1963. Traduziu obras importantes para o português, tais como o livro História da Matemática, de Carl Boyer. (VASCONCELOS; LEITE; MACEDO, 2012, p. 3141)

Analisando a magnitude e o poder com que a conjectura social no decorrer das eras afastou a mulher e a impediu de alcançar a esfera intelectual da sociedade, vimos que não era suficiente interessar-se ou aventurarse pela ciência, para, de fato, apropriar-se desse saber. Haviam muitos outros fatores e desafios a superar. Dessa forma, podemos traçar alguns pontos que as figuras descritas anteriormente possuíram em comum, que permitiu ou facilitou seu acesso ao conhecimento.

Nota-se que a maioria destas e de outras mais matemáticas vieram de famílias abastadas e socialmente influentes, que, graças às condições financeiras, fizeram com que elas pudessem buscar, muitas vezes fora de seu país, condições favoráveis para o estudo da Matemática. Além disso, tiveram geralmente algum tipo de parentesco, tutela, ou envolvimento com algum homem influente e/ ou estudioso na área da matemática, mostrando que, embora altamente capacitadas, muitas dessas mulheres dependeram de uma figura masculina para que pudessem mostrar suas habilidades para o mundo.

Nenhuma delas possuiu domínio apenas na área da Matemática, transitando durante suas carreiras nas diversas áreas das ciências exatas, como a física, a química, a astronomia, e, muitas vezes, em outras áreas como a filosofia, as artes, as letras. Ademais, é possível perceber a opção por não compor família, ou, quando muito, compor uma família longe da maneira usual, mostrando uma recusa em aderir aos moldes tradicionais familiares, que, por essência, aprisionavam a mulher em âmbito doméstico e em determinadas funções sociais. Nota-se, ainda, a comum morte prematura das mesmas, geralmente por doenças e/ou condições de saúde precárias.

\section{Considerações Finais}

O processo de reformulação das configurações sociais, principalmente no que tange as relações de gênero, evidenciado pelo movimento feminista, trouxe consigo avanços nas mais diversas esferas sociais. A Ciência foi uma dessas. As jovens que hoje chegam às escolas certamente veem com naturalidade a possibilidade de serem tão boas quanto ou até mesmo melhores que os meninos na disciplina de Matemática. Ignoram, mesmo que não intencionalmente, o quão difícil foi para que hoje, ao menos teoricamente, as mulheres pudessem ter acesso ao mesmo nível de conhecimento que os homens.

O trajeto dessa pesquisa, amparado pelas reflexões dos autores, chega a conclusões que reforçam "que a ausência histórica da mulher em contribuições nessas áreas foi um resultado de preconceitos culturais contra elas, e não qualquer déficit natural de talento ou de genialidade" 
(MARINOFF, 2008, p. 358 apud MOREIRA et al., 2010, p. 7). Além disso, pudemos evidenciar elementos cruciais para a construção milenar desse preconceito, responsável por incontáveis mortes, que por muito tempo manteve a mulher presa nas amarras do patriarcado e longe do saber formal/científico.

Mesmo sabendo que estudar as relações de gênero no campo da Matemática não se resume ao estudo de mulheres matemáticas, entendemos ser de extrema importância conhecer e reconhecer, até mesmo como uma forma de estímulo e inspiração, as, aqui chamadas, bravas transgressoras, que abriram caminhos para que muitas depois delas pudessem ter de volta aquilo que, como vimos, foi-lhes tirado.

Quando olhamos para a história de todas essas mulheres, podemos nos perguntar como seria a ciência se houvesse igualdade de acesso ao conhecimento tanto para os homens quanto para as mulheres. Maria Mitchell, citada por Sartori, 2006, disse 'Na minha juventude eu achava que as mulheres precisavam das ciências exatas, hoje eu acho que são as ciências exatas que precisam das mulheres' (MOREIRA et. al, 2010, p. 10).

Por fim, reconhecemos que muito já foi trilhado até então para amenizar os impactos causados pela desigualdade de gêneros no âmbito das ciências e dos saberes, porém muito ainda resta a caminhar. É essencial perceber que em nossas práticas - sejam elas pedagógicas, científicas, etc. - reproduzimos, diariamente, estereótipos e discursos que ainda alimentam a ideia, que já foi tida como fato, mas que hoje é facilmente refutada, de que a Matemática não é uma ciência para mulheres, e várias outras que decorrem dessa. Somente a partir desse reconhecimento e de atitudes que visem descontruir esse preconceito é que poderemos ver a balança, que ora ainda paira desigual, novamente equilibrar-se.

\section{Referências}

BOYER, Carl Benjamin. (1996). História da Matemática. $2^{\mathrm{a}}$ edição. São Paulo: Blücher.
CAVALARI, Mariana Feiteiro. (2010). "História, Mulheres e Educação Matemática". In: ENCONTRO NACIONAL DE EDUCAÇÃO MATEMÁTICA - ENEM, 10, Salvador. Disponível em: <http://www.gente.eti.br/ lematec/CDS/ENEM10/artigos/CC/T6_CC1355.pdf>. Acesso em: 24 abr. 2017.

FERNANDES, Maria da Conceição Vieira. (2006). A inserção e vivência da mulher na docência de matemática: uma questão de gênero. Dissertação (Mestrado em Educação) - Programa de Pós-Graduação em Educação, Centro de Educação da Universidade Federal da Paraíba. João Pessoa.

GEVEHR, Daniel Luciano; DE SOUZA, Vera Lucia. (2014). "As Mulheres e a Igreja na Idade Média: misoginia, demonização e caça às bruxas". Revista Acadêmica Licencia\&acturas, v. 2, n. 1, p. 113-121, jan-jun.

HUFF, Kendra D. (2011). Women in Mathematics: An Historical Account of Women's Experiences and Achievement. CMC Senior Theses. Paper 150. Disponível em: <http://scholarship.claremont.edu/cmc_theses/150>. Acesso em: 24 abr. 2017.

OLIVEIRA, Marceliane Dias. (2011). As Mulheres na Matemática. Monografia (Licenciatura em Matemática). Faculdade de Educação, Ciências e Letras do Sertão Central. Universidade Estadual do Ceará. Hidrolândia.

MOREIRA, Herivelto; GRAVONSKI, Isabel Ribeiro; DE CARVALHO, Marilia Gomes; KOVALESKI, Nádia V. J. (2010). "Mulheres Pioneiras nas Ciências: Histórias de Conquistas numa Cultura de Exclusão". In: CONGRESSO IBEROAMERICANO DE CIÊNCIA,TECNOLOGIA E GÊNERO, 8, Curitiba. Anais eletrônicos... Curitiba: UTFPR. Disponível em: < http://files.dirppg.ct.utfpr. edu.br/ppgte/eventos/cictg/conteudo_cd/E2_Mulheres Pioneiras_nas_Ci\%C3\%AAncias.pdf $>$. Acesso em: 20 abr. 2017.

MURARO, Rose Marie. (1993). "Breve introdução histórica”. In: KRAMER, Heinrich; SPRENGER, James. Malleus Maleficarum (O Martelo das Feiticeiras). 20 edição. Rio de Janeiro: Rosa dos Tempos, p. 5-17. 
NEGREIROS, Claudia Landin; SOUZA, Claudimara dos Santos; DE PAULA, Rejane Riggo. (2016). "De Hipátia À Mirzakhani: Um Percurso Pela Habilidade Feminina Para A Matemática". In: ENCONTRO NACIONAL DE EDUCAÇÃO MATEMÁTICA - ENEM, 12, São Paulo. Anais eletrôniocos. Disponível em: $<$ http://www. sbembrasil.org.br/enem2016/anais/pdf/7890_3786_ ID.pdf>. Acesso em: 09 mai. 2017.

TOSI, Lucia. (1998.) "Mulher e Ciência: a revolução científica, a caça às bruxas e a ciência moderna". Cadernos Pagu, v. 10, p. 369-397.

VASCONCELOS, Juscelândia Machado; LEITE, Bárbara Paula Bezerra; MACEDO, Luciana Maria de Souza. (2012). “Atuação Das Mulheres No Universo Da Matemática: O Caso Da Universidade Regional Do Cariri - URCA". In: SEMINÁRIO NACIONAL DE ESTUDOS E PESQUISAS "HISTÓRIA, SOCIEDADE E EDUCAÇÃO NO BRASIL", 9, João Pessoa. Anais eletrônicos. Disponível em: <http://www.histedbr. fe.unicamp.br/acer_histedbr/seminario/seminario $9 /$ PDFs/4.12.pdf>. Acesso em: 10 mai. 2017.

Data de recebimento: 25/05/2017.

Data de aceitação: 20/12/2017. 